Supplement of Biogeosciences, 15, 3883-3891, 2018

https://doi.org/10.5194/bg-15-3883-2018-supplement

C Author(s) 2018. This work is distributed under

the Creative Commons Attribution 4.0 License.

(c) (1)

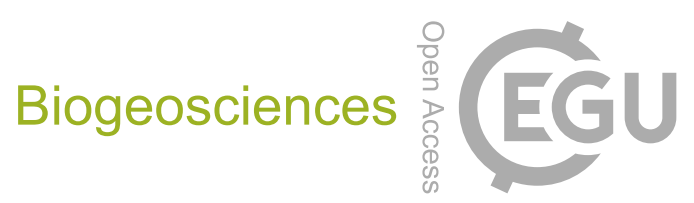

Supplement of

\title{
Immediate increase in isotopic enrichment in small mammals following the expansion of a great cormorant colony
}

Linas Balčiauskas et al.

Correspondence to: Linas Balčiauskas (linasbal@ekoi.lt)

The copyright of individual parts of the supplement might differ from the CC BY 4.0 License. 


\section{Supplements}

Table S1 Age and sex structure of the two dominant small mammal species trapped in the Juodkrantė great cormorant colony in 2015.

\begin{tabular}{lllll}
\hline Species & Sex & Adult & Subadult & Juveniles \\
\hline Apodemus flavicollis & Male & 18 & 17 & 11 \\
& Female & 12 & 15 & 15 \\
Myodes glareolus & Male & 7 & 5 & 5 \\
& Female & 6 & - & 6 \\
\hline
\end{tabular}

5 


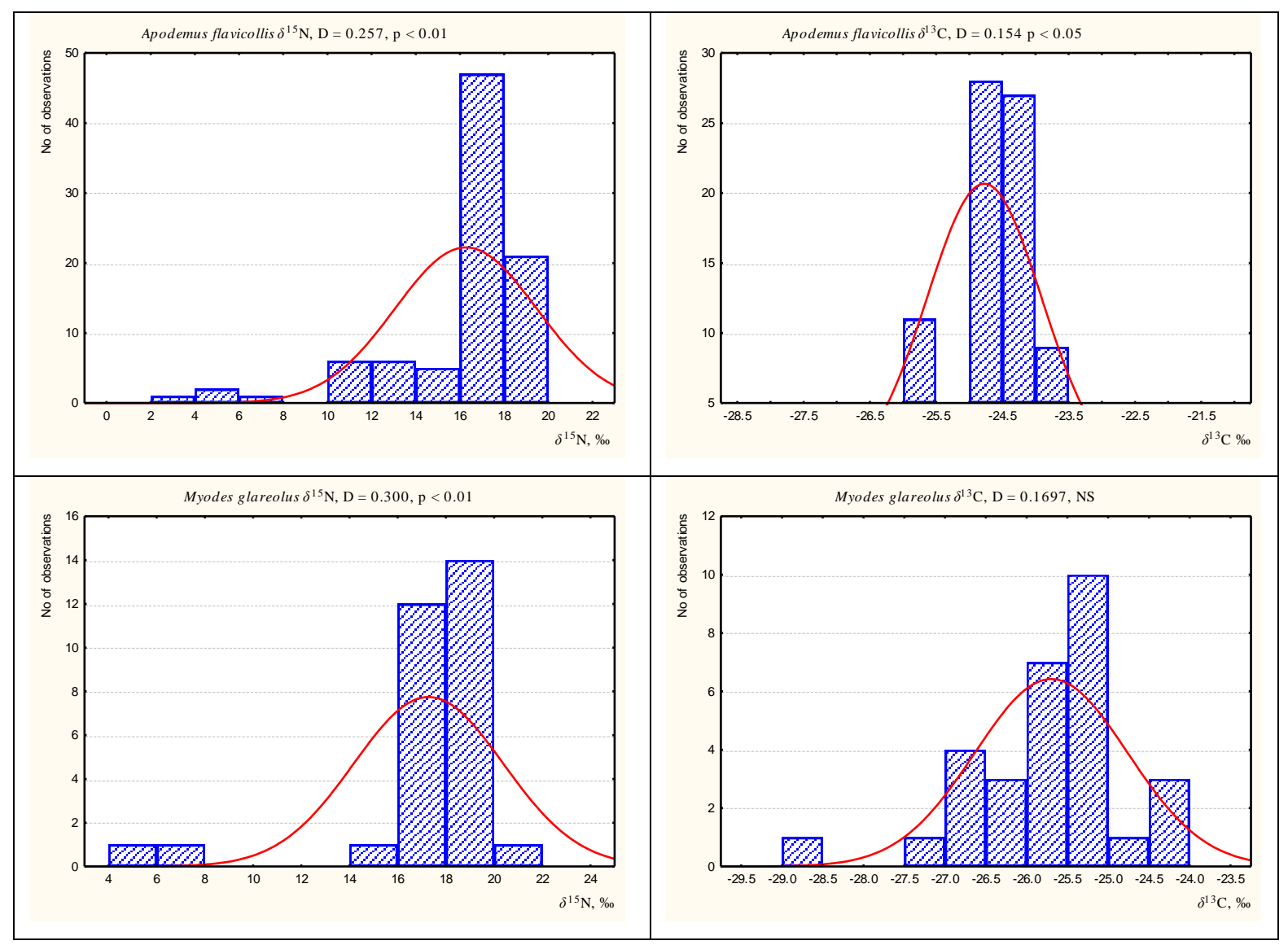

Figure S1. Distribution of $\delta^{13} \mathrm{C}$ and $\delta^{15} \mathrm{~N}$ values in the hair of Apodemus flavicollis and Myodes glareolus trapped in the Juodkrantė colony of great cormorants. Data for each species lumped across all zones. Normality tested using Kolmogorov-Smirnov's D. 

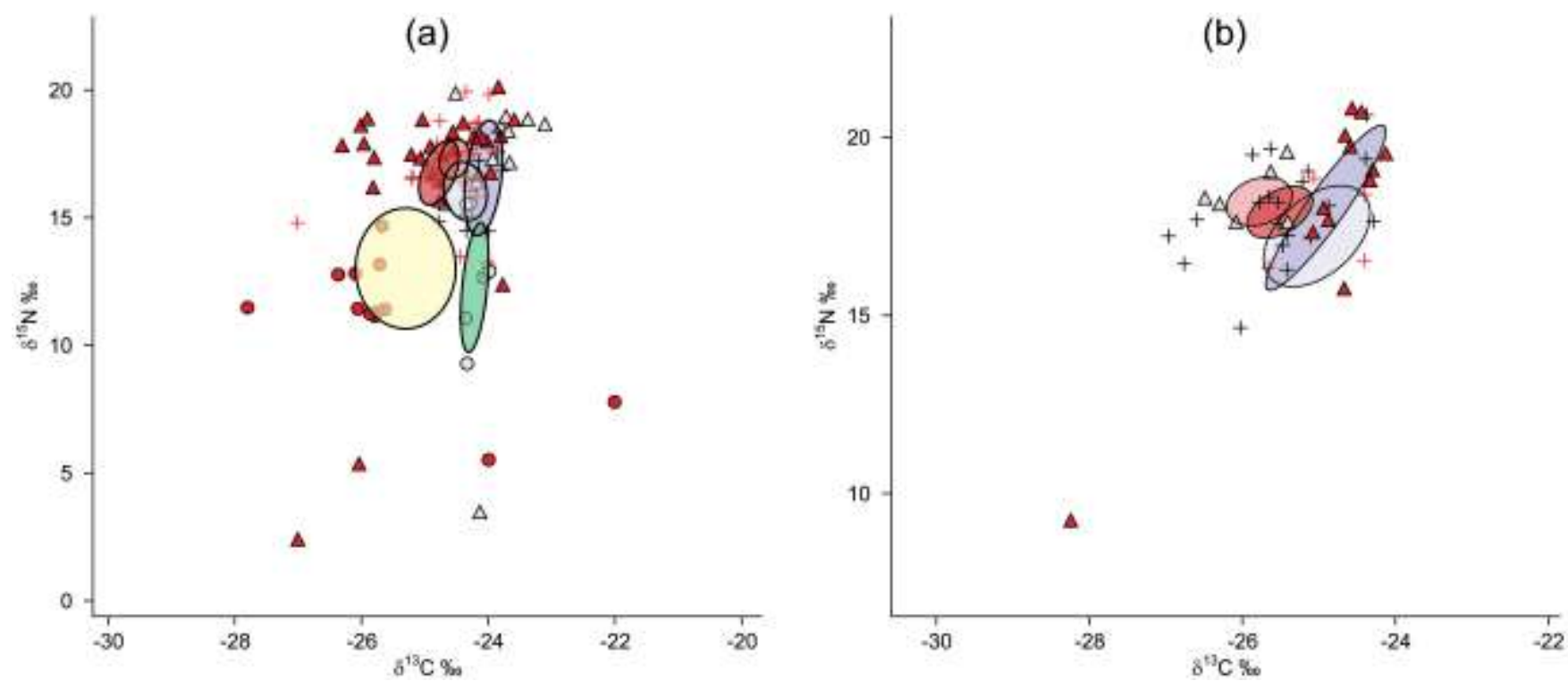

Figure S2. Central ellipses of $\delta^{13} \mathrm{C}$ and $\delta^{15} \mathrm{~N}$ distribution in the hair of Apodemus flavicollis (a) and Myodes glareolus (b), trapped in the Juodkrantė colony of great cormorants in 2014 (grey signs) and 2015 (red signs). Individuals from the colony zone are 5 represented by triangles, from the ecotone zone by crosses and from the control/expansion zone by circles. Central ellipse of the control zone in $\mathbf{2 0 1 4}$ are coloured in green and the expansion zone in 2015 in yellow. Central ellipses of the colony are shaded dark grey in 2014 and dark red in 2015, the ecotone zone is shaded light grey in 2014 and light red in 2015. 


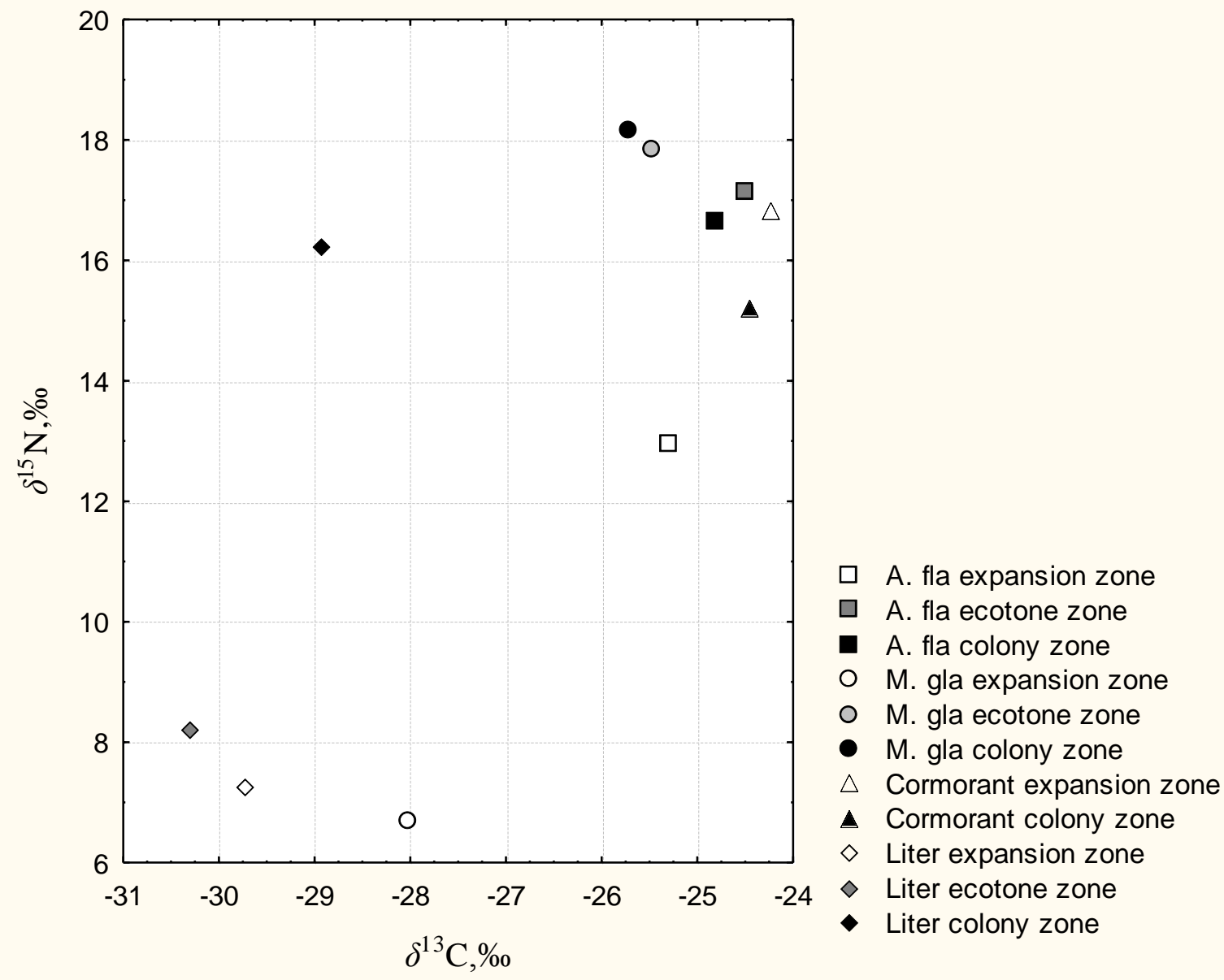

Figure S3. Central position of stable isotope ratios in litter, cormorant feathers and the hair of Apodemus flavicollis and Myodes 5 glareolus in different zones of the Juodkrantė colony of great cormorants in 2015. Key: Apodemus flavicollis, squares; Myodes glareolus, circles; great cormorants, triangles; litter, diamonds; expansion zone, white; ecotone zone, shaded; colony zone, black. 